\title{
ЖУРНАЛИСТИКА
}

УДК $070+821.161 .1$

\section{Е.И. Орлова}

\section{ИСТОРИЯ ЖУРНАЛИСТИКИ И ЛИТЕРАТУРЫ КАК УНИВЕРСИТЕТСКИЕ НАУКИ}

Московский государственный университет имени М. В. Ломоносова, Российская Федерация, 119991, Москва, Ленинские Горы, 1

Реформы в образовании, приведшие к гуманитарной катастрофе, побуждают университеты к поиску новых возможностей в изучении и преподавании истории литературы и журналистики, что может служить преодолению культурного разрыва. В статье говорится о четырех точках сближения этих дисциплин. Не менее важным представляется привлечение студентов к исследовательской работе. Одно из ее направлений (впрочем, конечно, не единственное) - изучение отечественной журналистики в ее связях с литературой. Правомерно и методологически совершенно обоснованно рассматривать журналистику как вид литературной деятельности: работа со словом, создание текста. Многие писатели, ныне ставшие бесспорными классиками, приходили в литературу через журналистику. Для других она была видом литературной работы, естественным для литератора образом жизни. Третьи вступали с ней в сложные, часто вынужденные либо даже конфликтные отношения. Как бы то ни было, каждый случай конкретен и требует изучения. Это первое.

Второе направление исследований - история критических оценок, создания литературной репутации писателя в его современности и затем в посмертной критике. Факультеты журналистики университетов вполне могут стать и уже становятся или стали научными центрами для работы в этом направлении. Ими накоплен огромный материал - это диссертации, научные статьи, монографии и т.д.

И конечно (в-третьих), одной из сфер тесного соприкосновения литературы и журналистики является публицистика. Такие исследования ведутся в университетах давно и продуктивно. В литературоведении в последние годы обсуждается термин «художественно-публицистическое единство», что убеждает в общности многих собственно филологических и историко-журналистских исследований.

Четвертое направление - журналистские выступления как претексты либо источники художественных произведений. Сюжет «Преступления и наказания», некоторые романы Н. Лескова, «Сентиментальные повести» М.Зощенко - этот ряд можно продолжать. Правомерны такие темы выпускных квалификационных работ, магистерских, кандидатских и докторских диссертаций, как, например, «М.Булгаков и журналистика», «Н.Гумилев и журналистика». Подобные исследования уже ведутся.

В современных условиях особенно важной становится роль гуманитарных наук, которые способствовали бы преодолению культурного разрыва или хотя бы ему противостояли. Библиогр. 7 назв.

Ключевые слова: гуманитарная катастрофа, образование, история литературы, история журналистики, преодоление культурного разрыва.

(C) Санкт-Петербургский государственный университет, 2016 


\section{HISTORY OF JOURNALISM AND LITERATURE AS UNIVERSITY DISCIPLINES}

\section{E. I. Orlova}

Moscow State Lomonosov University, 1, Leninskiye Gory, Moscow 119991, Russian Federation

Reforms in education, which have led to humanitarian catastrophe, are encouraging universities to seek new opportunities in teaching and learning the history of literature and journalism so that it could serve as a bridge for overcoming the cultural gap. The article describes 4 points of the discipline convergence. The matter of no less importance is the involvement of students into research work. One of its directions (though, of course, not the single one) is the studies of national journalism in its links with literature. It is quite correct and methodologically valid to consider journalism as a kind of literary activity as it contains work with the word and text creating. Many writers who have become undisputed classics now came to literature via journalism. For others it was a kind of literary work and a natural way of life for a man of letters. And still others came into complex, often forced, or even conflicting relations with it. Whatever it was, each case is specific and requires specific study. This is the first area of research.

The second one is the history of critical assessments, creation of the writer's literary reputation in its contemporaneity and then in posthumous criticism. University faculties of journalism may well be, and actually are becoming or have already become, such scientific centers. They have accumulated a wealth of material, such as theses, research papers, monographs, etc.

And, of course, (thirdly), one of the areas of a close contact between literature and journalism is publicism. Such research has been efficiently conducted at universities for a long time. In literary criticism in recent years, the term of "artistic and journalistic unity» has been discussed which persuades us in commonality of many philological, historical and journalistic research.

The fourth direction is journalistic performances as pretexts or sources of artistic works. The plot of "Crime and Punishment", some novels by N. Leskov, "Sentimental novels" by M. Zoshchenko is the series which goes on. Such topics of final qualifying works, as well as master's and doctoral theses as "M. Bulgakov and journalism", "N. Gumilyov and journalism" are quite legitimate. Such studies are already underway.

In modern conditions the role of humanities, which would help overcome the cultural gap, or at least could resist it, is becoming particularly important. Refs 7.

Keywords: humanitarian catastrophe, education, history of literature, history of journalism, bridging the cultural gap.

«Чем напряженнее становится состояние современного мира, тем яснее видны его саморазрушительные процессы. На глазах у нас происходит смена кода в культуре, не менее зловещая по последствиям, чем то было после Октябрьской революции в России. Опасность, которая таится в нарастающем терроризме, несравненно меньше, чем последствия изменений в культурной парадигме, агрессивно отрицающей общечеловеческую систему ценностей. Стремление принизить значение гуманистических ценностей, поставив во главу угла мораль “рыночной экономики”, - это еще одна из форм вульгарного материализма, как бы ни отличалась она по фразеологии от риторики марксистко-ленинского прагматизма» [Белая, с. 559]. Так писала Г.Белая в 2004 г. С тех пор правота ее слов только подтверждается. В этих условиях особенно важно установить, чем и как университетское образование могло бы способствовать преодолению культурного разрыва. Гуманитарная составляющая, в особенности филологическая, является в этом мощным ресурсом.

Современная ситуация в образовании отражает происходящую на наших глазах гуманитарную катастрофу и стимулирует ее дальнейшее усугубление. Школьная реформа проведена сверху при полном игнорировании мнений общественности, в том числе научного сообщества. Большим «достижением» смотрятся ежегодные рапорты о том, что «в (таком-то) нынешнем году ЕГЭ прошел без нарушений правил». Сказанные абсолютно серьезно, эти слова достойны сарказма Салтыкова- 
Щедрина. До тех пор, пока соблюдение законности подается как достижение, а не как норма, Щедрин будет жив. Судя по всему, ему суждено бессмертие.

Пора введения ЕГЭ была полна курьезов. В качестве «раздаточного материала» для тренировки школьникам было предложено стихотворение Пушкина «Телега жизни». Оно, как известно, существует в двух вариантах: один - нецензурный, другой - рассчитанный на публикацию. Для школьников был выбран именно первый вариант, в котором обсценные слова заменили, конечно, отточием, что не мешает вдумчивым подросткам, следуя пушкинскому ритму и способу рифмовки (из песни слова не выкинешь!), догадаться о пропущенном:

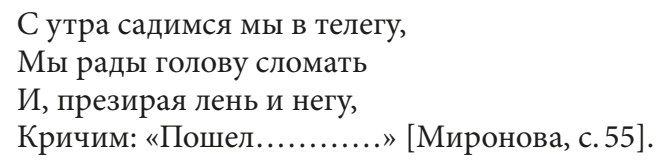

Это было смело. Автор пособия (которого, впрочем, гораздо точнее было бы назвать составителем: ведь не он же писал тексты!) не заметил шутки, которую литература сама сыграла с ним. Зато наблюдательные дети, надо думать, повеселились на славу. Ай да Пушкин! В это же время две знакомые мне старшеклассницы, дети, что называется, из хороших семей, не сумели объяснить, что значит «Порой опять гармонией упьюсь, / Над вымыслом слезами обольюсь». Они всерьез предположили, что речь идет о дружеской пирушке, на которой участники ее выпили лишнего («упьюсь»). Трудности встречаются и с попыткой прокомментировать строки «Мы ждем с томленьем упованья / Минуты вольности святой». Это ли не гуманитарная катастрофа?

Перечень некорректно поставленных вопросов в заданиях по литературе, попросту фактических ошибок в приводимых в них текстах был бы слишком длинным. Приведу только три примера. Первый: стихотворение А. Блока «Россия» приводится в таком виде: «Россия, нищая Россия, / Мне избы серые твои, / Твои мне песни ветровые - / Как слезы первые любви» [Зинин, с.57] (вместо блоковского «слезы первыя любви»). Второй: пушкинское «Поэту» дается без авторского подзаголовка («Сонет»), а вопрос к нему ставится, в частности, такой: «Укажите классический лирический жанр, к которому относится стихотворение». Правильным ответом считается «послание <или> посвящение» [Зинин, с. 67, 151] (так. - E. О.). Следовательно, ответ школьника, который напишет «сонет» и окажется тоже прав, будет признан неверным. Третий пример: стихотворение А.Ахматовой «Когда в тоске самоубийства...» до сих пор (по привычке советских лет) приводится без первых двух строф, то есть начиная со стиха «Мне голос был. Он звал утешно...» [Зинин, с. 136], перед которым дается отточие, отсутствующее у Ахматовой.

Почему я уделяю столько внимания литературе в школе, если речь идет об университетской науке? Но ведь университеты существуют в определенной социокультурной ситуации. Во-первых, меняется (уже изменился) общий и филологический уровень первокурсников - вчерашних школьников. Во-вторых, за школьной реформой не заставила себя ждать реформа в высшем образовании. Были ли они связаны между собой единым замыслом? Не берусь ответить на этот вопрос. Как бы то ни было, реформа высшей школы стала псевдонимом, под которым проводится не только действительное изменение, но одновременно с этим и сокращение выс- 
шего образования. Прекратило существование заочное отделение на факультете журналистики МГУ. Вечернее сузилось до 40 мест и теперь будет только платным. Во многих университетах страны магистратура упраздняется или уже упразднена. Это означает, что рано или поздно, а впрочем довольно скоро, там не будет и аспирантуры: в нее попросту некому будет поступать в условиях, когда вторая ступень высшего образования становится недоступной - или доступной лишь единицам выпускников, чьи родители будут в состоянии оплатить учебу в одной из столиц. Высшее образование в нашей стране, где так много талантливых людей и так низок жизненный уровень, может стать уделом лишь состоятельных.

Что означала «реформа» в вузах для базовых дисциплин? Конечно, их сокращение - что и произошло. На факультете журналистики МГУ, например, часы на историю литературы уменьшились вдвое, на историю отечественной журналистики - больше чем вдвое. Хорошо еще, что в конечном итоге - не сразу, конечно, - удалось синхронизировать два эти предмета, во многом родственные, и дать студентам более или менее достаточно времени на чтение литературы. Эти дисциплины не зря официально признаны самыми трудоемкими. И хотя школьные методики проникают все глубже в вузы и еще умножаются на формализацию учебного процесса, все же университетский стиль преподавания пока еще сохраняется, лучшие лекционные курсы остаются в полном смысле авторскими. Поэтому как раз исследовательское начало, истинно научная работа остается доступной для студентов, хотя и в сильно сокращенном виде (на спецкурсы и спецсеминары отводится по 18 часов, т.е. в 2 раза меньше, чем раньше; курсовые работы студенты пишут начиная лишь со 2-го курса; на работу над ВКР, включая ее написание, дается 3 недели, в отличие от целого семестра, как это было при выпуске специалистов).

Несмотря на это, и в последние годы мы получаем выпускные работы выдающегося качества. Например, Е. Яркова в дипломной работе 2014 г. о журнале конца XIX - начала XX в. «Артист» ввела в научный оборот до сих пор не учтенную даже в Большом каталоге Третьяковской галереи статью художника Николая Досекина, видного деятеля серебряного века, заведовавшего художественной частью Московских императорских театров, и одной из первых проследила творческую эволюцию ныне почти забытого живописца и скульптора: от Товарищества передвижных художественных выставок к модернизму и поискам нового стиля. Однако будут ли появляться выпускные квалификационные работы, которые имели бы не только учебное, но и научное значение, - пока еще вопрос. Ясно, однако, что требования к ВКР (привыкаем к новой аббревиатуре) неизбежно снижаются по сравнению с дипломной работой специалиста.

Итак, научная работа студентов будет существовать в урезанном виде. Преподаватель при этом не перестал, к счастью, быть ученым. Но что такое университетская наука? Можно ли говорить о ней как о какой-то особой отрасли науки в целом? Отличается ли она чем-нибудь от академической? Глубинно, методологически, - конечно, нет. Мы находимся в едином научном пространстве и пока что вольны выбирать себе предмет исследований - до тех пор, пока университетскую науку не призовут ограничить себя лишь тем, что имеет прямое отношение к преподаванию. Пока этого, к счастью, не произошло. Но даже если произойдет, всетаки до тех пор, пока курсы по истории журналистики и литературы будут читать 
в высшей школе, и наука в ней тоже останется. То же можно сказать и о других дисциплинах.

Есть, однако, некоторые особенности у «университетской науки»: новые идеи могут, и довольно быстро, проходить апробацию - пусть не в научном сообществе, а в студенческой аудитории, - но именно здесь они получают первую проверку. Одну из самых трудных, по признанию философов, категорий - смысл M.M. Бахтин определял так: это такое суждение, которое может служить ответом на вопрос [Бахтин, с. 350]. То, что не может служить ответом на вопрос, смысла не несет. Сильно упрощая, все же можно, кажется, применить эту формулу к университетской науке, сказав так: то, что нельзя объяснить первокурснику таким образом, чтобы он понял, не то чтобы не имеет смысла, но все-таки скорее всего нуждается в дальнейшей доработке или переработке.

Если же говорить об истории журналистики и литературы как университетских науках, то особенно продуктивным кажется мне изучение отечественной журналистики в ее связях с литературой (притом что это, конечно, не единственное направление историко-журналистских штудий, как и литературных). Называемая в XIX в. «срочной словесностью», журналистика и создает во многом литературный процесс, сама являясь его частью и одновременно организуя его, в чем состоит ее неповторимая роль. Даже отделяясь от литературы в период Первой мировой войны [Жирков] и потом становясь средством пропаганды по преимуществу ${ }^{1}$ журналистика тем не менее связана с литературой по самой своей природе: работа со словом, создание текста. Правомерно и методологически совершенно обоснованно рассматривать журналистику как вид литературной деятельности. Многие авторы, ныне ставшие бесспорными классиками, приходили в литературу через журналистику (ясно, однако, что это был далеко не единственный путь). Для других она была видом литературной работы, естественным для литератора образом жизни. Третьи вступали с ней в сложные, часто вынужденные либо конфликтные отношения. Как бы то ни было, каждый случай конкретен и требует изучения.

Но это лишь одно направление исследований. Второе - история критических оценок, создания литературной репутации писателя в его современности и затем в посмертной критике. Такие исследования ведутся, конечно, не только в университетах. Фундаментальный труд по истории советской журналистики создавался в 1960-е годы в ИМЛИ, двухтомник «Литературный процесс и русская журналистика конца XIX — начала XX в.» - там же в 1970-е. Но в последние десятилетия такие исследования как бы уходят в менее заметную (но не менее важную) область академической науки - в группы, подготавливающие собрания сочинений русских писателей, зато становятся там - пусть в неизбежно кратком виде - обязательной составляющей научных комментариев. Однако и факультеты журналистики университетов вполне могут стать и уже становятся или стали такими научными центрами. Студенческая подготовка от этого только выигрывает. Например, вступительный реферат в аспирантуру, написанный выпускником 2008 г. Р. Поддубцевым, лег в основу его статьи, опубликованной в журнале «Вопросы литературы»

1 Но как именно это происходило, как работали собственные внутренние процессы в журналистике - еще далеко не исследовано. Возможно, что появление в начале XX в. типа тонкого журнала, дальнейшее развитие литературной критики и поэтики как науки, их постепенное разделение тоже приводило к специализации в журналистике. 
(«Экфрасис у Андрея Платонова: поэтика визуальности»), а затем в переводе на английский - в журнале «Russian Studies in Literature». Кстати, «Вопросы литературы», ведущий литературоведческий журнал, за годы 2003-2014 опубликовал, по моим подсчетам, 7 или 8 статей аспирантов факультета журналистики МГУ - случай вовсе небывалый для многолетней практики этого издания, чьими авторами всегда были не меньше чем кандидаты наук. Научное значение имели и дипломные работы Н. Гусева (о журналистской деятельности В. Одоевского) и Е. Сартакова (о публицистике Гоголя). Теперь все трое - преподаватели МГУ. Но будет ли приток преподавательских сил в университеты через 10 лет? Вот тревожный вопрос, ответа на который у меня снова нет.

И конечно (в-третьих), одной из сфер тесного соприкосновения литературы и журналистики является публицистика. Исследования в этой области ведутся в университетах давно. Вспомним кандидатскую диссертацию ныне широко известного профессора Воронежского университета Л. Кройчика. Посвященная беллетризованному фельетону 1920-х годов, она была одной из первых научных работ, написанных, в частности, на материале фельетонистики М.Булгакова еще тогда, когда к изучению его наследия наша наука лишь приступала, претерпевая в этом большие сложности: в 1960-е и даже 1970-е годы Булгаков находился в положении уже не запрещенного, но и еще не разрешенного, каждая статья о нем проходила в печать, в том числе научную, с большим трудом. В 1981 г. автору этих строк посчастливилось защитить диссертацию на тему «Проблема изучения авторской позиции писателя-сатирика (из опыта советской литературной критики 20-х годов)». Героями этой работы были М. Зощенко и М. Булгаков - что совершенно не явствует из заглавия, - но, чтобы обезопасить прохождение работы в ВАК, имена этих писателей диссертационный совет факультета журналистики МГУ посоветовал «убрать» вглубь текста. Теперь, в начале XXI века, особенно отчетливо видно, что возрождение булгаковского наследия, начавшись в критике 1960-х годов, было продолжено большей частью в российских университетах. Тогда же на факультете журналистики МГУ окончательно сформировалась научная школа, соединявшая филологические исследования с изучением истории журналистики, в лингвистике - языка периодической печати, позднее - других, новых СМИ. В числе ее основателей - профессора А. Западов, Д. Розенталь, Г. Солганик, А. Бочаров, Г. Белая. (Знаменательно, что в 1976 г. Г. Белая и Г. Солганик защитили докторские диссертации, столь разные, на факультете журналистики МГУ. Одна была посвящена стилевым закономерностям советской прозы 20-х годов, другая - газетной лексике и источникам ее формирования.)

Четвертое направление - журналистские выступления как претексты либо источники художественных произведений. Сюжет «Преступления и наказания», некоторые романы Н. Лескова, «Сентиментальные повести» М.Зощенко - этот ряд можно продолжать. Правомерны такие темы выпускных квалификационных работ, магистерских, кандидатских, а может быть, и докторских диссертаций, как, например, «М. Булгаков и журналистика», «Н. Гумилев и журналистика». Такие исследования уже ведутся.

Конечно, сближение наших двух наук ни в коем случае не должно привести к объединению преподаваемых дисциплин. При общности в методологии (культурно-исторический, возможно - историко-функциональный подходы, сравни- 
тельное либо имманентное исследование поэтики художественного и публицистического текста и т.д.) это две самостоятельные науки, хотя во многом родственные, но неслиянные. Они должны взаимодействовать, это продуктивно, как любые другие междисциплинарные исследования, но при этом каждая должна оставаться самой собой и как наука, и как учебный предмет.

Итак, намеченные четыре направления в научных исследованиях литературы и журналистики кажутся перспективными и сами по себе, и для университетской науки, поскольку могут способствовать преодолению культурного разрыва, хотя я далека от мысли о том, что достаточно только одного этого - и проблема будет решена. В заключение же попробуем посмотреть, по необходимости кратко, в какую общую систему встраивается современная ситуация в образовании. Сравнивая конец XX - начало XXI в. с первым пореволюционным десятилетием, Г. Белая констатировала: «Капитуляция перед массовой культурой поразительно похожа на “организованное упрощение культуры”, которое было девизом и плебейской, и элитарной критики 20-х годов» [Белая, с. 559]. А если взять эту ситуацию в более широком историческом контексте? Какие же периоды нашей истории претерпело просвещение? Петровские преобразования и их развитие в условиях крепостного права, когда «народ цивилизуют под плетьми и обучают грамоте в застенке» (М. Волошин). - Реформы Александра II. - Печально известный «циркуляр о кухаркиных детях» Александра III. - Планомерное уничтожение цвета национальной культуры в сочетании с развитием «вширь» - достижением всеобщей грамотности, а затем, через несколько десятилетий, обязательного среднего образования один из величайших парадоксов советской системы, при том что последнее нужно считать, конечно, ее огромным завоеванием. Казалось бы, век спустя логично было ожидать такого же расширения высшей школы, которая стала бы если не обязательной, то общедоступной. Как видим, этого не произошло. В нынешних условиях особенно важной становится роль гуманитарных наук, которые способствовали бы преодолению культурного разрыва, хотя бы ему противостояли. В конце концов, «евро-американская модель развития предполагает активный переход от постиндустриального общества к информационному. Очевидно, что роль России в этом процессе специфична. Сомнительно, что можно говорить об успешном преодолении фазы индустриального развития, когда было сформировано большинство высококлассных мировых брендов. Россия в этом процессе была в роли “догоняющего”. Все бренды, которыми может гордиться наша страна, носят историкокультурный характер» (цит. по: [Семенова, с. 176]; курсив мой. - Е. О.).

И еще одно соображение хотелось бы здесь привести, размышляя о стандартизации и тенденции к «укрупнению» в образовании в наше время. Г. Тульчинский пишет: «Только уникальное глобально, и только уникальные, неповторимые, оригинальные явления и достижения получают возможность войти в общемировое культурное, экономическое пространство» [Тульчинский, с. 150].

Сказанные по другому поводу, эти слова современного философа оказываются совершенно верными и в отношении образования.

\section{Литература и источники}

Бахтин М. М. Эстетика словесного творчества. М.: Искусство, 1979. 423 с.

Белая Г.А. Дон Кихоты революции - опыт побед и поражений. М.: РГГУ, 2004. 623 с. 
Жирков Г. В. Журналистика России: от золотого века до трагедии. 1900-1918 гг. Ижевск: Ин-т компьютерных исследований, 2014. 382 с.

Зинин С. А. ЕГЭ-2013. Литература. Самое полное издание типовых вариантов заданий. М.: Астрель, 2013. $160 \mathrm{c}$.

Миронова Ю. С. ЕГЭ. Литература. Раздаточный материал тренировочных тестов. СПб.: Тригон, 2009. $96 \mathrm{c.}$

Семенова А. Л. Исторические дисциплины в профессиональной подготовке журналистов // Семенова А.Л. Сопряжение идей... Сопряжение смыслов... Великий Новгород: Новгород. гос. ун-т, 2015. 280 c.

Тульчинский Г.Л. Глобализация, массовая культура и бренд России: угрозы или «окна возможностей»? // PR-технологии в информационном обществе: матер. IV Всероссийской научно-практической конф. (Санкт-Петербург, 30-31 марта 2007). Ч. 1. СПб.: СПбПУ, 2007. 560 с.

Для цитирования: Орлова Е.И. История журналистики и литературы как университетские науки // Вестник СПбГУ. Серия 9. Филология. Востоковедение. Журналистика. 2016. Вып. 4. С. 162-169.

DOI: $10.21638 / 11701 /$ spbu09.2016.412.

\section{References}

Bakhtin M. M. Estetika slovesnogo tvorchestva [Aesthetics of verbal creation]. Moscow, Iskusstvo Publ., 1979. 423 p. (in Russian)

Belaya G. A. Don Kikhoty revoliutsii - opyt pobed i porazhenii [Don Quixotes of revolution - experience of victories and defeats]. Moscow, Russian State Univ. for the Humanities Press Publ., 2004. 623 p. (in Russian)

Zhirkov G. V. Zhurnalistika Rossii: ot zolotogo veka do tragedii. 1900-1918 gg. [Journalism in Russia: From the Golden Age to tragedy. 1900-1918]. Izhevsk, Institute komp'iuternykh issledovanii Publ., 2014. 382 p. (in Russian)

Semenova A.L. Исторические дисциплины в профессиональной подготовке журналистов [Historic disciplines in professional preparation of journalists]. Semenova A. L. Sopriazhenie idei... Sopriazhenie smyslov... [Linking ideas... Linking meanings]. Veliky Novgorod, Novgorod State Univ. Publ., 2015. 280 p. (in Russian)

Tul'chinskii G. L. Globalizatsiia, massovaia kul'tura i brend Rossii: ugrozy ili “okna vozmozhnostei”? [Globalization, mass culture and brand of Russia: Threats or opportunities?]. PR-tekhnologii v informatsionnom obshchestve. Proceedings of the IV Vserossiiskaia nauchno-prakticheskaia konferentsiia [PRtechnologies and information communication. Proceedings of the IV Russian Research and Practical Conference]. St. Petersburg, 30-31 March 2007. St. Petersburg, Peter the Great St. Petersburg Polytechnic Univ. Publ., 2007, pr. 1. 560 p. (in Russian)

For citation: Orlova E. I. History of Journalism and Literature as University Disciplines. Vestnik SPbSU. Series 9. Philology. Asian Studies. Journalism, 2016, issue 4, pp. 162-169. DOI: 10.21638/11701/spbu09.2016.412.

Статья поступила в редакцию 16 марта 2016 г.

Статья рекомендована в печать 27 июня 2016 г.

Контактная информация:

Орлова Екатерина Иосифовна - доктор филологических наук, профессор; ekatorlova@yandex.ru Orlova Ekaterina I. — Doctor of Philology, Professor; ekatorlova@yandex.ru 